\title{
Factors associated with 5-year survival in older heart transplant recipients
}

Arman Kilic, MD, Eric S. Weiss, MD, MPH, David D. Yuh, MD, Ashish S. Shah, MD, and John V. Conte, MD

Objectives: The aim of the present study was to identify the predictors of 5-year survival in elderly patients undergoing orthotopic heart transplantation (OHT).

\begin{abstract}
Methods: A review of the United Network for Organ Sharing database was conducted of recipients 60 years old or older undergoing OHT from 1995 to 2004. The variables were compared between the 5-year survivors and the patients who died within 5 years of OHT. A multivariate logistic regression model was constructed using the covariates significantly associated with 5-year survival on univariate analysis.
\end{abstract}

Results: A total of 5330 elderly patients underwent OHT during the study period. Of these patients, 3492 $(65.5 \%)$ were 5-year survivors, $1580(29.6 \%)$ had died within 5 years of OHT and were considered controls, and $258(4.8 \%)$ were lost to follow-up. The predictors of improved 5-year survival included younger age (odds ratio [OR], 0.97; 95\% confidence interval [CI], 0.95-1.00; $P=.03$ ), lower creatinine (OR, 0.92; 95\% CI, 0.87-0.98; $P=.01$ ), white race (OR, $1.23 ; 95 \% \mathrm{CI}, 1.02-1.49 ; P=.03)$, shorter ischemic time (OR, $0.93 ; 95 \% \mathrm{CI}, 0.87-0.99 ; P=.02$ ), and younger donor age (OR, 0.99; 95\% CI, 0.99-1.00; $P=.03)$. The following significantly reduced the odds of surviving to 5 years: mechanical ventilation $(\mathrm{OR}, 0.48 ; 95 \% \mathrm{CI}$, $0.33-0.71 ; P<.001)$, hypertension (OR, 0.79; 95\% CI, 0.69-0.91; $P=.001)$, and diabetes (OR, 0.79; 95\% CI, 0.67-0.92; $P=.003)$. Ventricular assist device data were only available for 2538 patients $(49.6 \%)$. When added to the multivariate model, the use of a ventricular assist device significantly reduced the odds of surviving 5 years after OHT (OR, $0.63 ; 95 \%$ CI, $0.50-0.81 ; P<.001)$.

Conclusions: In the present study of more than 5000 elderly OHT patients, younger recipient age, white race, lower creatinine, younger donor age, and shorter ischemic time were associated with improved 5-year survival. In contrast, bridging with a ventricular assist device, mechanical ventilation, hypertension, and diabetes significantly decreased the odds of 5-year survival. These findings might be useful for prognostication in this higher risk patient population. (J Thorac Cardiovasc Surg 2012;143:468-74)

The United States Census Bureau has projected that the proportion of the population that is elderly will increase in coming years, with the number of those aged 65 years or older doubling in the next 2 decades. ${ }^{1}$ This will undoubtedly lead to a greater number of older patients presenting to cardiac surgeons. It is therefore imperative that the outcomes in this patient population be studied further in an effort to optimize the therapeutic results.

In the realm of heart transplantation, the effect of advancing age on outcomes is especially important, secondary to the lack of donor organs and the need to rationally allocate these limited resources. Initially performed only in patients younger than 50 years old, orthotopic heart transplantation

From the Division of Cardiac Surgery, Department of Surgery, Johns Hopkins Medical Institutions, Baltimore, Md.

Disclosures: Authors have nothing to disclose with regard to commercial support.

Supported by departmental funds from the Department of Surgery, Johns Hopkins Hospital, Baltimore, Maryland.

Received for publication Aug 1, 2011; accepted for publication Oct 20, 2011.

Address for reprints: John V. Conte, MD, Division of Cardiac Surgery, Department of

Surgery, Johns Hopkins Hospital, Blalock 618, 600 N Wolfe St, Baltimore, MD

21287 (E-mail: jconte@jhmi.edu).

$0022-5223 / \$ 36.00$

Copyright (C) 2012 by The American Association for Thoracic Surgery

doi:10.1016/j.jtcvs.2011.10.036
(OHT) is being increasingly performed in older patients despite the conflicting data. Some centers view advanced age as a contraindication to transplantation, citing data demonstrating poorer graft and patient survival in the elderly., ${ }^{2,3}$ Other groups have found equivalent survival in older and younger recipients. ${ }^{4,5}$ Regardless, it is clear that careful preoperative selection of candidates is essential for acceptable survival. Although transplant outcomes stratified by age have been studied quite extensively, the predictors of survival in older OHT recipients are yet to be determined. The aim of the present study was to identify the factors predictive of 5-year survival in OHT recipients aged 60 years or older.

\section{MATERIALS AND METHODS \\ Data Source}

The source of data for the present study was the Standard Transplant Analysis and Research files from the United Network for Organ Sharing (UNOS). This database provides de-identified patient-level data; thus, the present study was granted exempt status by our institutional review board.

\author{
Study Design \\ The analysis was limited to patients aged 60 years or older undergoing \\ OHT from 1995 to 2004. Those undergoing retransplantation or
}




\section{Abbreviations and Acronyms \\ $\mathrm{CI} \quad=$ confidence interval \\ OHT $=$ orthotopic heart transplantation \\ $\mathrm{OR}=$ odds ratio \\ UNOS $=$ United Network for Organ Sharing \\ $\mathrm{VAD}=$ ventricular assist device}

multivisceral transplant were excluded. The control cohort consisted of patients who died within 5 years of OHT. The data were compared between these patients and those surviving at least 5 years after OHT. The patients who were lost to follow-up (alive, but with $<5$ years of follow-up) were excluded.

\section{Variables}

A total of 32 recipient, donor, hemodynamic, and transplant variables were compared between the controls and survivors. Univariate analysis was conducted using the $t$ test for continuous variables and the chi-square test for categorical variables. Multivariate logistic regression analysis was performed, incorporating significant predictors on univariate analysis, with the odds ratios (ORs) and 95\% confidence intervals (CIs) calculated for the covariates. Variables that had more than $15 \%$ missing data were excluded from entry into the multivariate model. $P<.05$ was considered significant on both univariate and multivariate analyses. These analyses were performed using STATA, version 11, software (StataCorp, College Station, Tex).

\section{RESULTS}

\section{Study Population}

A total of 18,455 adult ( $\geq 18$ years) patients underwent first-time, single-organ OHT during the study period in the UNOS database. Of these, $5330(28.9 \%)$ were recipients 60 years old or older. In the present elderly cohort, 1580 patients $(29.6 \%)$ had died within 5 years of OHT and were included in the control group and 3492 patients $(65.5 \%)$ had survived at least 5 years. The remaining 258 patients $(4.8 \%)$ were lost to follow-up (alive but with $<5$ years of follow-up) and were thus excluded.

The patients included in the present analysis had a mean age of $63.7 \pm 3.0$ years. The distribution of patient age by 5-year category was as follows: 60 to 64.9 years $(\mathrm{n}=3302 ; 65.1 \%), 65$ to 69.9 years $(\mathrm{n}=1564 ; 30.8 \%)$, and 70 years or older $(n=206 ; 4.1 \%)$. Most patients were males $(\mathrm{n}=4224 ; 83.3 \%)$. The mean body mass index was $25.5 \pm 4.2 \mathrm{~kg} / \mathrm{m}^{2}$, and $4385(86.5 \%)$ were white.

\section{Baseline Characteristics}

A comparison of the baseline characteristics demonstrated that the 5-year survivors were significantly younger than the control group (Table 1). The survivors also had a lower serum creatinine than the controls. A greater percentage of survivors were white. Fewer survivors required mechanical ventilation or intra-aortic balloon pump before transplantation. Fewer survivors had comorbidities such as hypertension and diabetes. The ischemic time was also shorter in the survivor cohort. The hemodynamic data were similar between the 2 groups. The indications for transplantation were also similar. The donors for the 5 -year survivors were significantly younger. Otherwise, the demographic variables of the donors were similar between the 2 groups. Data on ventricular assist device (VAD) therapy as bridge-to-transplantation data were only available for 2538 patients $(49.6 \%)$, because this variable was collected only in the later years of the study period. Fewer survivors were bridged to OHT with a VAD than nonsurvivors.

\section{Univariate and Multivariate Analyses}

Univariate logistic regression analysis identified several potential predictors of 5-year survival. The significant predictors on univariate analysis included younger age, lower serum creatinine, white race, shorter ischemic time, and younger donor age (Table 2). Mechanical ventilation, intra-aortic balloon pump use, diabetes, hypertension, and VAD therapy significantly decreased the likelihood of 5-year survival on univariate analysis.

Multivariate analysis was conducted incorporating all these significant univariate predictors, except for VAD therapy, because $50 \%$ of the data were missing for that covariate. In the multivariate model, a lower recipient creatinine and white race were each found to independently improve the odds of 5-year survival (Table 3). Younger recipient age within the elderly cohort was also found to improve the odds of 5-year survival. The recipient factors associated with a decreased likelihood of survival included mechanical ventilation before transplantation, hypertension, and diabetes. A significant inverse correlation was found between the number of these adverse factors (ventilation, hypertension, diabetes) and the proportion of 5-year survivors, such that patients who had none of these factors had $72 \% 5$-year survivors and patients with 2 or all 3 of these factors had $60 \%$ 5 -year survivors $(P<.001$; Figure 1$)$. The donor variables associated with improved 5-year survival included younger donor age and shorter ischemic time. Patients with a donor age older than 40 years and ischemic time longer than 4 hours had a $12 \%$ absolute reduction in the proportion of 5 -year survivors compared with recipients with a donor age younger than 25 years and an ischemic time shorter than 2 hours $(P<.001$; Figure 2$)$. Although VAD therapy was initially excluded from the multivariate model because of the high percentage of missing data, when it was added, VAD therapy was found to significantly and independently reduce the likelihood of 5-year survival (OR, $0.63 ; 95 \% \mathrm{CI}$, $0.50-0.81 ; P<.001)$.

\section{DISCUSSION}

The demand for heart transplantation continues to outweigh the supply of available organs. Approximately 3000 patients with end-stage heart disease are on the wait 
TABLE 1. Baseline characteristics

\begin{tabular}{|c|c|c|c|}
\hline Variable & Controls $(n=1580)$ & 5-y survivors $(n=3492)$ & $P$ value \\
\hline \multicolumn{4}{|l|}{ Recipient } \\
\hline Age $(y)$ & $63.9 \pm 3.1$ & $63.6 \pm 2.9$ & $.005^{*}$ \\
\hline Male gender & $1309 / 1580(82.9)$ & 2915/3492 (83.5) & .58 \\
\hline White race & $1329 / 1580(84.1)$ & $3056 / 3492(87.5)$ & $.001 *$ \\
\hline Body mass index $\left(\mathrm{kg} / \mathrm{m}^{2}\right)$ & $25.6 \pm 4.3$ & $25.5 \pm 4.2$ & .18 \\
\hline Transplant in later era (1999-2004) & $927 / 1580(58.7)$ & 2079/3492 (59.5) & .56 \\
\hline Creatinine & $1.6 \pm 1.3$ & $1.4 \pm 1.2$ & $<.001^{*}$ \\
\hline Mechanical ventilation before $\mathrm{OHT}$ & $71 / 1580(4.5)$ & $73 / 3492(2.1)$ & $<.001^{*}$ \\
\hline Intra-aortic balloon pump & $113 / 1580(7.2)$ & $167 / 3492(4.8)$ & $.001 *$ \\
\hline Days on wait list & $239.3 \pm 351.6$ & $243.3 \pm 354.4$ & .71 \\
\hline Hypertension & $690 / 1495(46.2)$ & $1331 / 3295(40.4)$ & $<.001^{*}$ \\
\hline Diabetes & $369 / 1514(24.4)$ & $680 / 3346(20.3)$ & $.001 *$ \\
\hline Cytomegalovirus positive & $549 / 784(70.0)$ & $1253 / 1785(70.2)$ & .93 \\
\hline \multicolumn{4}{|l|}{ Heart failure etiology } \\
\hline Dilated cardiomyopathy & $1287 / 1580(81.5)$ & $2880 / 3492(82.5)$ & .38 \\
\hline Coronary artery disease & $217 / 1580(13.7)$ & $447 / 3492(12.8)$ & .36 \\
\hline Valvular disease & $41 / 1580(2.6)$ & $96 / 3492(2.8)$ & .75 \\
\hline Hypertrophic cardiomyopathy & $3 / 1580(0.2)$ & $17 / 3492(0.5)$ & .12 \\
\hline Congenital heart disease & $4 / 1580(0.3)$ & $10 / 3492(0.3)$ & .84 \\
\hline Bridged with VAD & $160 / 779(20.5)$ & $262 / 1759(14.9)$ & $<.001^{*}$ \\
\hline \multicolumn{4}{|l|}{ Donor } \\
\hline Age $(y)$ & $34.1 \pm 13.9$ & $32.6 \pm 13.5$ & $<.001^{*}$ \\
\hline Male gender & $1051 / 1580(66.5)$ & $2354 / 3492(67.4)$ & .53 \\
\hline White race & $1184 / 1580(74.9)$ & 2652/3492 (75.6) & .44 \\
\hline Body mass index $\left(\mathrm{kg} / \mathrm{m}^{2}\right)$ & $25.5 \pm 5.2$ & $25.7 \pm 5.3$ & .13 \\
\hline Creatinine & $1.2 \pm 1.5$ & $1.2 \pm 1.5$ & .96 \\
\hline Antihypertensive agents & 229/1539 (14.9) & 466/3432 (13.6) & .22 \\
\hline Diabetes & 28/1558 (1.8) & $73 / 3452(2.1)$ & .46 \\
\hline Cytomegalovirus positive & $937 / 1566(59.8)$ & 2040/3451 (59.1) & .63 \\
\hline \multicolumn{4}{|l|}{ Recipient-donor matching } \\
\hline Identical blood type & $1365 / 1580(86.4)$ & 3035/3492 (86.9) & .61 \\
\hline HLA match ( $\geq 2$ antigen match) & $360 / 1304(27.6)$ & $871 / 2952(29.5)$ & .21 \\
\hline Cytomegalovirus match & $431 / 781(55.2)$ & $982 / 1777(55.3)$ & .97 \\
\hline \multicolumn{4}{|l|}{ Hemodynamic } \\
\hline Mean PAP (mm Hg) & $29.7 \pm 10.0$ & $29.3 \pm 10.5$ & .26 \\
\hline PVR (dyne $\cdot \mathrm{s} / \mathrm{cm}^{5}$ ) & $2.5 \pm 1.8$ & $2.5 \pm 2.1$ & .33 \\
\hline $\mathrm{CO}(\mathrm{L} / \mathrm{min})$ & $4.3 \pm 1.4$ & $4.4 \pm 1.4$ & .06 \\
\hline PCWP (mm Hg) & $19.8 \pm 8.8$ & $19.5 \pm 8.9$ & .28 \\
\hline TPG (mm Hg) & $9.9 \pm 5.6$ & $9.7 \pm 6.0$ & .45 \\
\hline \multicolumn{4}{|l|}{ Transplantation } \\
\hline Biatrial technique & $1177 / 1537$ (76.6) & $2536 / 3414(74.3)$ & .08 \\
\hline Ischemic time (hr) & $3.1 \pm 1.1$ & $3.0 \pm 1.0$ & $.002 *$ \\
\hline
\end{tabular}

Data presented as mean \pm standard deviation or number (percentage). OHT, Orthotopic heart transplantation; VAD, ventricular assist device; HLA, human leukocyte antigen; $P A P$, pulmonary artery pressure; $P V R$, pulmonary vascular resistance; $C O$, cardiac output; $P C W P$, pulmonary capillary wedge pressure; $T P G$, transpulmonary pressure gradient. * Statistically significant.

list on any given day, with only 2000 undergoing transplantation each year. ${ }^{6}$ Given this discrepancy and the need to rationally allocate these limited resources, strict eligibility criteria have been developed and are continually revised to ensure acceptable probability of long-term success.

The recipient upper age limit is one such criterion that has been debated in the surgical community. Some centers view advanced age as a contraindication to transplantation, citing several single-institution studies that have demonstrated worse short- and long-term survival in older patients. ${ }^{3,4,7,8}$ These data have been echoed in the findings of multiinstitutional reports, including those using databases from UNOS, the Registry of the International Society for Heart and Lung Transplantation, and the Transplant Cardiologists Research Database, which have all demonstrated an adverse effect on survival with increasing recipient age..$^{9-11}$ However, several studies have shown equivalent survival between older and younger cohorts. ${ }^{6,12}$ These latter data, in addition to the 
TABLE 2. Univariate logistic regression analysis

\begin{tabular}{|c|c|c|}
\hline Variable & $\begin{array}{c}\text { OR of 5-y survival } \\
(95 \% \mathbf{C I}) \\
\end{array}$ & $\begin{array}{c}P \\
\text { value }\end{array}$ \\
\hline \multicolumn{3}{|l|}{ Recipient } \\
\hline Age (increasing) & $0.97(0.95-0.99)$ & $.005^{*}$ \\
\hline Male gender & $1.05(0.89-1.23)$ & .58 \\
\hline White race & $1.32(1.12-1.57)$ & $.001 *$ \\
\hline Body mass index (increasing) & $0.99(0.98-1.00)$ & .18 \\
\hline Transplant in later era (1999-2004) & $1.10(0.90-1.34)$ & .35 \\
\hline Creatinine (increasing) & $0.89(0.83-0.95)$ & $.001^{*}$ \\
\hline Mechanical ventilation before $\mathrm{OHT}$ & $0.45(0.33-0.63)$ & $<.001^{*}$ \\
\hline Intra-aortic balloon pump & $0.65(0.51-0.83)$ & $.001^{*}$ \\
\hline Days on wait list (increasing) & $1.00(1.00-1.00)$ & .71 \\
\hline Hypertension & $0.79(0.70-0.89)$ & $<.001 *$ \\
\hline Diabetes & $0.79(0.69-0.91)$ & $.002 *$ \\
\hline Cytomegalovirus positive & $1.01(0.84-1.21)$ & .93 \\
\hline \multicolumn{3}{|l|}{ Heart failure etiology } \\
\hline Dilated cardiomyopathy & $1.07(0.92-1.25)$ & .38 \\
\hline Coronary artery disease & $0.92(0.77-1.10)$ & .36 \\
\hline Valvular disease & $1.06(0.73-1.54)$ & .75 \\
\hline Hypertrophic cardiomyopathy & $2.57(0.75-8.79)$ & .13 \\
\hline Congenital heart disease & $1.13(0.35-3.61)$ & .84 \\
\hline Bridged with VAD & $0.68(0.54-0.84)$ & $<.001 *$ \\
\hline \multicolumn{3}{|l|}{ Donor } \\
\hline Age (increasing) & $0.99(0.99-1.00)$ & $<.001^{*}$ \\
\hline Male gender & $1.04(0.92-1.18)$ & .53 \\
\hline White race & $1.06(0.92-1.21)$ & .44 \\
\hline Body mass index (increasing) & $1.01(1.00-1.02)$ & .13 \\
\hline Creatinine (increasing) & $1.00(0.96-1.04)$ & .96 \\
\hline Antihypertensive agents & $0.90(0.76-1.07)$ & .22 \\
\hline Diabetes & $1.18(0.76-1.83)$ & .46 \\
\hline Cytomegalovirus positive & $0.97(0.86-1.10)$ & .63 \\
\hline \multicolumn{3}{|l|}{ Recipient-donor matching } \\
\hline Identical blood type & $1.05(0.88-1.25)$ & .61 \\
\hline HLA match ( $\geq 2$ antigen match) & $1.10(0.95-1.27)$ & .21 \\
\hline Cytomegalovirus match & $1.00(0.85-1.19)$ & .97 \\
\hline \multicolumn{3}{|l|}{ Hemodynamic } \\
\hline Mean PAP (increasing) & $1.00(0.99-1.00)$ & .26 \\
\hline PVR (increasing) & $0.98(0.95-1.02)$ & .34 \\
\hline CO (increasing) & $1.05(1.00-1.09)$ & .06 \\
\hline PCWP (increasing) & $1.00(0.99-1.00)$ & .28 \\
\hline TPG (increasing) & $1.00(0.98-1.01)$ & .45 \\
\hline \multicolumn{3}{|l|}{ Transplantation } \\
\hline Biatrial technique & $0.88(0.77-1.02)$ & .09 \\
\hline Ischemic time (increasing) & $0.91(0.86-0.97)$ & $.002 *$ \\
\hline
\end{tabular}

idea that the chronologic age might not be a reflection of the physiologic age, have led some centers to advocate transplantation in elderly recipients. Regardless, it is clear that careful selection of candidates is necessary to ensure acceptable outcomes in older patients.

To appropriately select older candidates for transplantation, an understanding of the factors associated with
TABLE 3. Multivariate logistic regression analysis

\begin{tabular}{lcc}
\hline \multicolumn{1}{c}{ Variable } & $\begin{array}{c}\text { OR for 5-y survival } \\
(\mathbf{9 5} \% \mathbf{C I})\end{array}$ & $\begin{array}{c}\boldsymbol{P} \\
\text { value }\end{array}$ \\
\hline Recipient & & \\
Age (increasing) & $0.98(0.95-1.00)$ & $.03^{*}$ \\
White race & $1.23(1.02-1.49)$ & $.03^{*}$ \\
Creatinine (increasing) & $0.92(0.87-0.98)$ & $.01^{*}$ \\
Mechanically Ventilated & $0.48(0.33-0.71)$ & $<.001^{*}$ \\
Intra-aortic balloon pump & $0.79(0.59-1.06)$ & .12 \\
Hypertension & $0.79(0.69-0.91)$ & $.001^{*}$ \\
$\quad$ Diabetes & $0.79(0.67-0.92)$ & $.003^{*}$ \\
Donor & & $.03^{*}$ \\
$\quad$ Age (increasing) & $0.99(0.99-1.00)$ & \\
Transplantation & & $.02^{*}$ \\
$\quad$ Ischemic time (increasing) & $0.93(0.87-0.99)$ & \\
\hline
\end{tabular}

Bridging with VADs was excluded from multivariate analysis because of the high percentage of missing data for that covariate. $O R$, Odds ratio; $C I$, confidence interval; $V A D$, ventricular assist device. *Statistically significant.

survival in this cohort is necessary. The aim of the present study was to evaluate 32 recipient, donor, hemodynamic, and recipient-donor matching variables in a large multiinstitutional database for the purpose of identifying those associated with 5-year survival. A principal finding was that younger recipient age, white race, and lower creatinine levels were associated with improved 5-year survival. The donor factors leading to improved 5-year survival included younger donor age and shorter ischemic time. In addition, mechanical ventilation, hypertension, and diabetes in the recipient significantly reduced the odds of surviving to 5 years after transplantation.

\section{Recipient Age}

The finding that younger age within the elderly cohort is associated with improved survival confirms previous data that increasing age as a continuous variable is associated with decreasing survival. The key issue has been finding an appropriate age cutoff for transplantation, which has proved difficult, because previous studies have used different cutoffs for their data analyses, impeding comparisons. As mentioned previously, however, selecting a strict cutoff might not be necessary, because viewing the patients with regard to their comorbidities and overall health, in addition to their chronologic age, might be more prudent in predicting the outcomes. That recipient age was an independent predictor of survival might also reflect a shorter life expectancy, in addition to the increasing comorbidities that accompany advancing age.

\section{White Race}

Emerging evidence has suggested that race might have a significant effect on the outcomes of thoracic organ transplantation. In an analysis of more than 20,000 adult OHT recipients, black Americans were found to have significantly 


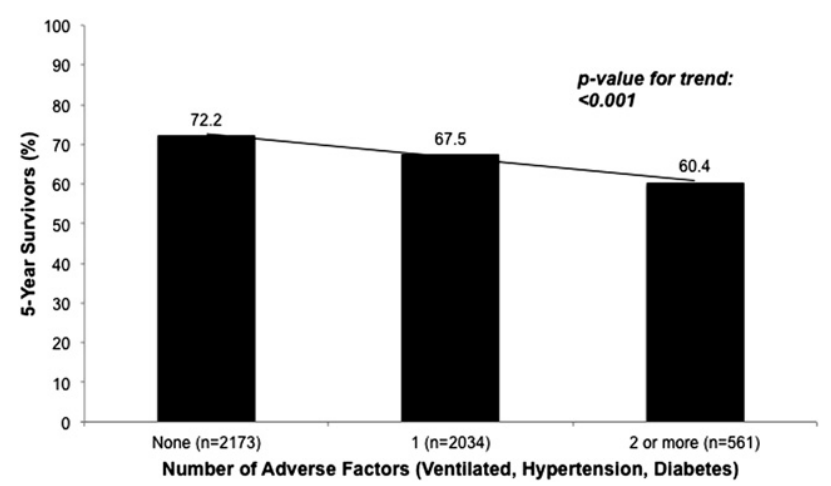

FIGURE 1. Proportion of 5-year survivors by number of adverse risk factors (mechanical ventilation, hypertension, diabetes).

worse survival than other races. ${ }^{13}$ In the present study, white race increased the odds of 5 -year survival by $23 \%$ in elderly OHT patients. Whether these survival discrepancies are attributable to biologic differences or socioeconomic issues such as access to care, or both, remains to be elucidated.

\section{Serum Creatinine}

In addition to younger recipient age and white race, a lower serum creatinine was associated with improved 5 -year survival. Renal function is known to decline with age, and elderly patients are particularly susceptible to chronic kidney disease and end-stage renal failure. ${ }^{14}$ In a single-institution study, the risk of postoperative renal failure was significantly greater in elderly recipients and was a primary reason for worse long-term survival compared with younger patients. ${ }^{15}$ The results from our study suggest that those elderly patients with relatively greater impaired renal function preoperatively might be at an especially greater risk of adverse outcomes and/or earlier death after transplant. Therefore, it appears that in elderly patients who are more prone to renal failure, the optimization of renal function before transplantation and close attention to preserving this function in the postoperative period might be prudent to achieving acceptable outcomes in this patient population.

\section{Donor Age and Ischemic Time}

With regard to the donor variables, the significant predictors of 5-year survival included younger donor age and shorter ischemic time. Substantial previous data have been published on the effect of donor age on outcomes after OHT. In a report of all adult heart transplantations in the International Society for Heart and Lung Transplantation registry, increasing donor age as a continuous variable was a significant predictor of 1-, 5-, and 10-year mortality. ${ }^{10}$ This effect of donor age on outcomes is thought to be in part a result of an increased risk of transplant coronary artery disease with older donors and its associated increase in post-transplant morbidity and mortality. ${ }^{16}$ In our study,

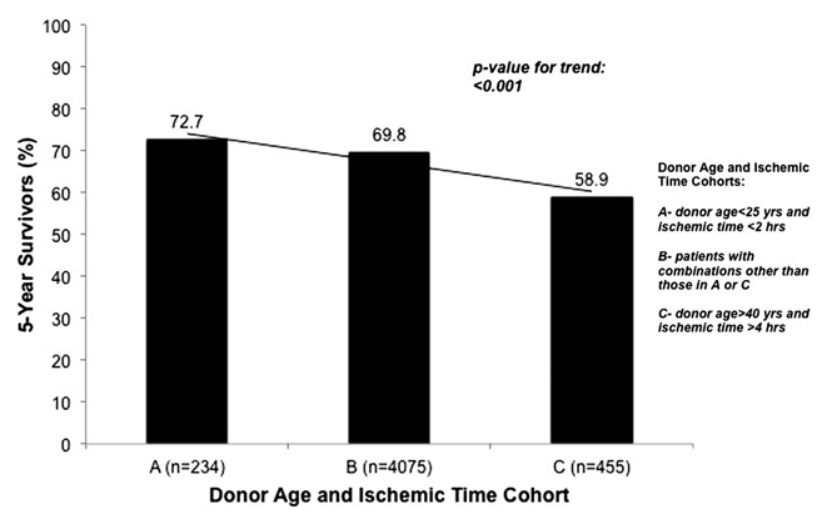

FIGURE 2. Proportion of 5-year survivors by donor age and ischemic time cohorts.

the elderly population was not spared from the adverse effect of increasing donor age. Although the outcomes in the elderly might be adversely affected with increasing donor age, it is important to note that expanding the donor pool by including marginal donors does increase the organ recovery rates by $20 \%$ to $30 \%$ annually, thereby helping to address the critical shortage of available organs for OHT. ${ }^{17}$ With regard to the ischemic time, an analysis of the UNOS database demonstrated that the adverse effect of an increasing ischemic time on survival after transplantation is dependent on donor age. ${ }^{18}$ Moreover, older donor hearts were found to be particularly susceptible to the adverse effects of prolonged ischemic times, and younger donor hearts were better able to tolerate prolonged ischemia. These findings were echoed in our analysis of the elderly population.

\section{Hypertension}

The factors that significantly decreased the odds of surviving to 5 years after transplantation included hypertension, diabetes, and mechanical ventilation. As demonstrated in Figure 1, a 12\% absolute reduction was found in the proportion of 5-year survivors for those patients with 2 or more of these factors compared with those with none of them. The observation that hypertension reduced survival might be because it is an established risk factor for cardiovascular disease. Additionally, hypertension has been shown to be associated with a greater risk of coronary allograft vasculopathy after OHT. ${ }^{19}$ Coronary allograft vasculopathy, in turn, is a significant cause of both short- and long-term mortality after OHT. ${ }^{10}$

\section{Diabetes Mellitus}

Diabetes mellitus has been considered a relative contraindication to OHT in some centers because of the potentially worse outcomes and worsening of diabetes resulting from steroid immunosuppressive therapy. Previous studies have demonstrated that patients with diabetes undergoing OHT 
experience a greater rate of infection, rejection, and/or transplant coronary artery disease compared with those without diabetes. ${ }^{20,21}$ It is no surprise, therefore, that diabetes was adversely associated with survival in the present study. Nondiabetic elderly recipients are not entirely spared, however, because increasing age has been shown to be a significant risk factor for the development of new-onset diabetes after OHT. ${ }^{22}$ Whether survival differences exist between OHT patients with pretransplant diabetes versus recipients in whom diabetes develops in the post-transplant period remains to be studied.

\section{Mechanical Ventilation Before Transplantation}

Mechanical ventilation before transplantation was also associated with a reduced likelihood of 5-year survival. This factor is likely a reflection of the acuity of transplant and the cardiopulmonary reserve of the recipient. Additionally, requiring mechanical ventilation likely translates to an intensive care unit stay, which itself has adverse effects secondary to factors such as nutritional depletion and nosocomial infection, among others. In addition, respiratory failure requiring preoperative ventilation is a risk factor for prolonged ventilation postoperatively. In a study of more than 800 patients, prolonged mechanical ventilation was associated with a greater risk of long-term mortality, particularly in the elderly and those with poor prehospital functional status. ${ }^{23}$

\section{VAD Therapy}

VAD therapy as a bridge-to-transplantation was a variable that was not routinely collected until the latter part of our study period; therefore, we had a high proportion of missing data. Although excluded from the final model, VADs were found to be a significant independent predictor of decreased survival on multivariate analysis incorporating other significant univariate predictors. The effect of VAD therapy on post-transplant outcomes remains controversial, because some centers with significant experience have demonstrated excellent outcomes in this patient cohort and some registry data have demonstrated an adverse effect of VAD bridging on survival after OHT. ${ }^{24,25}$ The effect of VADs on the postOHT outcomes in the elderly remains an area of future investigation.

\section{Study Limitations}

The present study had several limitations. A principal limitation was the potential reporting biases that could be present because UNOS is a multi-institutional database. Additionally, as with other large national data sets, reporting is not complete in some instances; therefore, some variables have missing data. Other variables such as VAD therapy were missing for most patients because that variable was not being routinely collected during the study period. Finally, other potentially predictive variables were not included in the present analysis, including surgeon volume, center volume, other comorbidities, and preservation methods of the donor organ, including solution used and application method.

\section{CONCLUSIONS}

As the population ages, the number of elderly patients considered for and undergoing OHT will undoubtedly increase. The present study analyzed multiple recipient, donor, and transplant data to identify the predictors of 5-year survival in patients older than 60 years. In the present large cohort of more than 5000 elderly patients, younger recipient age, white race, lower creatinine level, younger donor age, and shorter ischemic time were found to improve 5-year survival. Mechanical ventilation, hypertension, and diabetes decreased the likelihood of 5-year survival. Bridging with VADs, although not included in the final model because of missing data, was also found to decrease the odds of survival, independent of the other significant covariates. These data have provided a comprehensive analysis of the factors associated with 5-year survival in elderly OHT recipients and should serve as a useful guide in prognostication in this higher risk patient cohort.

\section{References}

1. United States Census Bureau. U.S. Bureau of Census Web site. Available at: http://www.census.gov. Accessed July 15, 2011.

2. Favaloro R, Diez M, Bertolotti A, Diez M, Favaloro L, Gomez C, et al. Orthotopic heart transplantation in elderly patients: a 10-year experience at a single center. Transplant Proc. 2004;36:1692-4.

3. Peraira JR, Segovia J, Fuentes R, Ortiz P, Ortigosa J, Silva L, et al. Differential characteristics of heart transplantation in patients older than 60 years. Transplant Proc. 2003;35:1959-61.

4. Demers P, Moffatt S, Oyer PE, Hunt SA, Reitz BA, Robbins RC. Long-term results of heart transplantation in patients older than 60 years. J Thorac Cardiovasc Surg. 2003;126:224-31.

5. Morgan JA, John R, Weinberg AD, Remoli R, Kherani AR, Vigilance DW, et al. Long-term results of cardiac transplantation in patients 65 years of age and older: a comparative analysis. Ann Thorac Surg. 2003;76:1982-7.

6. Health Resources and Services Administration, U.S. Department of Health and Human Services. Organ Procurement and Transplantation Network Web site. Available at: http://optn.transplant.hrsa.gov. Accessed July 15, 2011.

7. Bull DA, Karwande SV, Hawkins JA, Neumayer LA, Taylor DO, Jones KW, et al. Long-term results of cardiac transplantation in patients older than sixty years: UTAH Cardiac Transplant Program. J Thorac Cardiovasc Surg. 1996;111:423-7.

8. Borkon AM, Muehlebach GF, Jones PG, Bresnahan DR Jr, Genton RE, Gorton ME, et al. An analysis of the effect of age on survival after heart transplant. J Heart Lung Transplant. 1999;18:668-74

9. Weiss ES, Nwakanma LU, Patel ND, Yuh DD. Outcomes in patients older than 60 years of age undergoing orthotopic heart transplantation: an analysis of the UNOS database. J Heart Lung Transplant. 2008;27:184-91.

10. Taylor DO, Stehlik J, Edwards LB, Aurora P, Christie JD, Dobbels F, et al. Registry of the International Society for Heart and Lung Transplantation: twentysixth official adult heart transplant report-2009. J Heart Lung Transplant. 2009;28:1007-22.

11. Bourge RC, Naftel DC, Costanzo-Nordin MR, Kirklin JK, Young JB, Kubo SH, et al. Pretransplantation risk factors for death after heart transplantation: a multiinstitutional study. The Transplant Cardiologists Research Database Group. J Heart Lung Transplant. 1993;12:549-62.

12. Blanche C, Matloff JM, Denton TA, Czer LS, Fishbein MC, Takkenberg JJ, et al. Heart transplantation in patients seventy years of age and older: initial experience. Ann Thorac Surg. 1996;62:1731-6. 
13. Allen JG, Weiss ES, Arnaoutakis GJ, Russell SD, Baumgartner WA, Conte JV, et al. The impact of race on survival after heart transplantation: an analysis of more than 20,000 patients. Ann Thorac Surg. 2010;89:1956-63.

14. Stevens LA, Viswanathan G, Weiner DE. Chronic kidney disease and end-stage renal disease in the elderly population: current prevalence, future projections, and clinical significance. Adv Chronic Kidney Dis. 2010;17:293-301.

15. Marelli D, Kobashigawa J, Hamilton MA, Moriguchi JD, Kermani R, Ardehali A, et al. Long-term outcomes of heart transplantation in older recipients. J Heart Lung Transplant. 2008;27:830-4.

16. El Oakley RM, Yonan NA, Simpson BM, Deiraniya AK. Extended criteria for cardiac allograft donors: a consensus study. J Heart Lung Transplant. 1996;15:255-9.

17. Jacobbi LM, McBride VA, Etheredge EE, McDonald JC, Cooper ES, Frey D, et al. The risks, benefits, and costs of expanding donor criteria. Transplantation. 1995;60:1491-6.

18. Russo MJ, Chen JM, Sorabella RA, Martens TP, Garrido M, Davies RR, et al. The effect of ischemic time on survival after heart transplantation varies by donor age: an analysis of the United Network for Organ Sharing database. J Thorac Cardiovasc Surg. 2007;133:554-9.

19. Valantine H. Cardiac allograft vasculopathy after heart transplantation: risk factors and management. J Heart Lung Transplant. 2004;23:S187-93.
20. Marelli D, Laks H, Patel B, Kermani R, Marmureanu A, Patel J, et al. Heart transplantation in patients with diabetes mellitus in the current era. J Heart Lung Transplant. 2003;22:1091-7.

21. Morgan JA, John R, Weinberg AD, Colletti NJ, Mancini DM, Edwards NM. Heart transplantation in diabetic recipients: a decade review of 161 patients at Columbia Presbyterian. J Thorac Cardiovasc Surg. 2004;127:1486-92.

22. Martinez-Dolz L, Almenar L, Martinez-Ortiz L, Arnau MA, Chamorro C, Moro J, et al. Predictive factors for development of diabetes mellitus postheart transplant. Transplant Proc. 2005;37:4064-6.

23. Chelluri L, Im KA, Belle SH, Schulz R, Rotondi AJ, Donahoe MP, et al. Longterm mortality and quality of life after prolonged mechanical ventilation. Crit Care Med. 2004;32:61-9.

24. Park Y, Kherani AR, Vigilance DW, Cheema FH, Oz MC, Naka Y. Does bridging to transplantation with a left ventricular assist device adversely affect posttransplantation survival? A comparative analysis of mechanical versus inotropic support. J Thorac Cardiovasc Surg. 2003;126:1188-90.

25. Patlolla V, Patten RD, De Nofrio D, Konstam MA, Krishnamani R. The effect of ventricular assist devices on post-transplant mortality — an analysis of the United Network for Organ Sharing Thoracic Registry. J Am Coll Cardiol. 2009;53: 264-71. 